\title{
A further demonstration of the learned safety effect in food-aversion learning*
}

\author{
ROBERT C. BOLLES, ANTHONY L. RILEY \\ and \\ BARBARA LASKOWSKI \\ University of Washington, Seattle, Wash. 98105
}

\begin{abstract}
Using Kalat's procedure, a group of rats exposed twice to a novel food, once $4 \mathrm{~h}$ and again $1 / 2 \mathrm{~h}$ before poisoning, showed no more aversion to the food than comparable rats exposed just once $4 \mathrm{~h}$ before poisoning. This finding, together with the results from various control animals, indicates that food-aversion learning is reduced by prior learning that the food is safe.
\end{abstract}

One of the most interesting and important discoveries in recent years is that rats can associate the taste of a novel food with the consequences of ingesting it (Garcia $\&$ Koelling, 1966). Although the basic phenomenon of learned food aversions had been known for some time (e.g., Rzoska, 1953), it remained for Garcia and Koelling to emphasize that such learning presents a challenge to current theories of learning. Current theories all require that the consequences of a response follow it closely in time if they are to have either a reinforcing or a punishing effect upon the strength of the response. Yet here was learning occurring with a delay of hours between the response, eating, and the consequence, illness.

According to Revusky \& Garcia (1970), learning with long-delayed consequences is possible at all only because the taste-illness situation provides a kind of closed system. Revusky and Garcia propose further that learning occurs because this system is peculiarly free from interference. Thus, in the case of visual stimuli, a kaleidoscopic array of stimulation intervenes between the sight of the critical food and the subsequent illness, so no association between the critical taste stimulus and the consequence can be formed. This argument is not entirely convincing. For one thing, birds show an aversion to the sight of the food rather than to its taste (Wilcoxon, Dragoin, \& Kral, 1971). Another consideration is that the interference hypothesis fails to explain the critical role played by the novelty of the critical food in learned aversions. Finally, the interference hypothesis does not tell us why there is a temporal gradient of delay of illness. Thus, if no feeding and, thus, no other taste intervenes between the ingestion of the novel meal and subsequent illness, then what produces the gradual loss of association with increasing delays?

*Supported by Research Grant GB-20801 from the National Science Foundation. Requests for reprints should be sent to Robert C. Bolles, Department of Psychology, University of Washington, Seattle, Washington 98105.
All of these phenomena are tied together by a recent theoretical proposal by Kalat (Kalat, 1971; Kalat \& Rozin, in press; Rozin \& Kalat, 1970). We may think of the rat as treating a new food suspiciously at first (neophobia). Thus, the animal has a set to learn about the consequences of ingesting it. Then, Kalat suggests, if there are no ill consequences of ingestion, the rat will learn that the new food is safe. The more experience the rat has with no ill effect, the more learned safety there will be and the less likely it will be to show an aversion if it should subsequently become sick. This explains the temporal gradient. The novelty effect can be interpreted as the animal's having previously learned the safety of familiar foods. The species differences in the stimuli that control learned aversions can be readily seen as differences in sensory input into the neophobia-safety system.

To test the learned safety hypothesis against the interference argument, Kalat compared the learned aversion to a novel food (casein hydrolysate) under three different acquisition conditions (Kalat, 1971). For one group (Group 4), ingestion of the test food was followed by induced illness $4 \mathrm{~h}$ later. Another group (Group $1 / 2$ ) had illness induced $1 / 2 \mathrm{~h}$ after the meal, and these Ss, as would be expected, showed a stronger aversion to the test food than the Ss in Group 4. The important group (Group 41/2) sampled the test food twice, once $4 \mathrm{~h}$ before illness was induced and again $31 / 2 \mathrm{~h}$ later, $1 / 2 \mathrm{~h}$ before being made ill. The prediction from the interference hypothesis is that these Ss should have a strong "trace" and minimal interference because they had sampled the food just $1 / 2 \mathrm{~h}$ before becoming ill; they should, therefore, be expected to show an aversion at least as strong as the Ss in Group $1 / 2$. However, Kalat found that Ss in Group $4 \frac{1}{2}$ showed no more aversion than Ss in Group 4. The reason, according to the learned safety interpretation, is that they had $3 \frac{1}{2} \mathrm{~h}$ to learn the food was safe, almost as much time as the Ss in Group 4.

However, these results leave one important question unanswered. It is not clear whether Kalat's Ss were learning that the test food was safe or whether they were learning that it had beneficial caloric consequences during the interval preceding the induction of illness. The test food was casein hydrolysate, a high-calorie food which is useful in this kind of experimentation because of its high salience (Kalat \& Rozin, 1970). Thus, it would seem desirable to determine if Groups 4 and $4 \frac{1}{2}$ both showed a slight aversion because both groups had approximately the same opportunity to learn that casein hydrolysate was safe or because both groups were given approximately equal opportunities to learn that ingesting this substance had beneficial aftereffects. To 


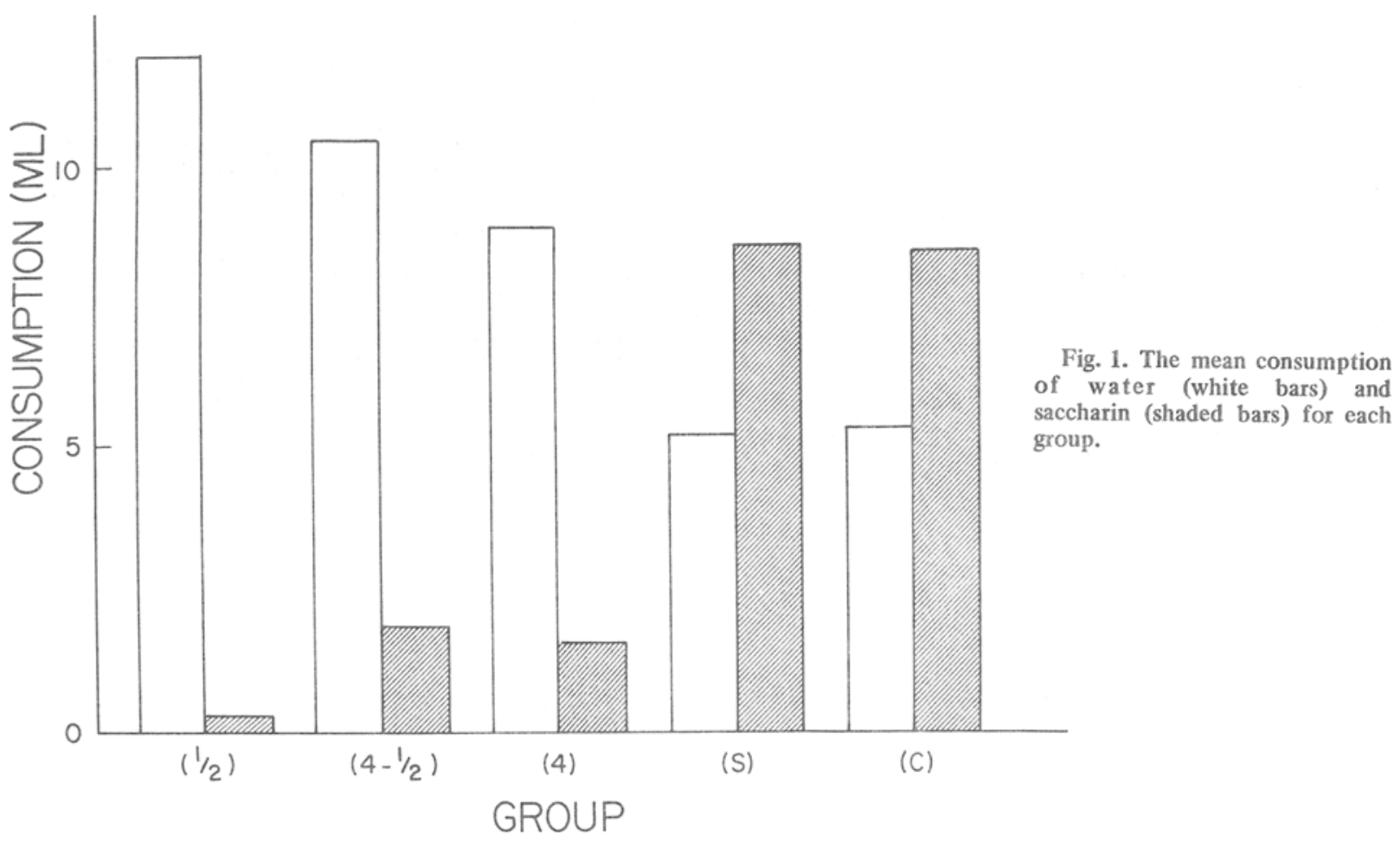

answer this question, the present study replicated Kalat's experiment, with saccharin rather than casein hydrolysate as the test food.

\section{METHOD}

\section{Subjects}

The Ss were 30 experimentally naive female rats of Long-Evans descent between 90 and 120 days of age. They were maintained on ad lib food but were water deprived throughout the experiment.

\section{Apparatus}

The Ss were housed in individual wire mesh cages. In the front of each cage were two openings into which graduated Richter tubes were placed for presentation of water and/or saccharin solution ( $1 \mathrm{~g} /$ liter $)$.

\section{Procedure}

The Ss were given 20 min access to water in a Richter tube once a day until all of the $S s$ were approaching and drinking from the tube within a period of 2 sec. At this point training began. Differential treatments were administered to five groups of Ss. Group 4 was presented with saccharin for $10 \mathrm{~min}$, followed $4 \mathrm{~h}$ later by poisoning. Group $4 \frac{1}{2}$ was presented with saccharin for $10 \mathrm{~min}$, followed $3 \frac{1}{2} \mathrm{~h}$ later by a second presentation of saccharin for $2 \frac{1}{2} \mathrm{~min}$. Poisoning occurred $1 / 2 \mathrm{~h}$ after the second exposure to saccharin. Group $1 / 2$ was given $2 \frac{1}{2}$ min access to saccharin and poisoned $1 / 2 h$ later. Group $S$ received the same treatment as Group $1 / 2$, except that a saline injection replaced poisoning. Group $\mathrm{C}$, serving as a saccharin control, was given $2 \frac{1}{2} \mathrm{~min}$ access to saccharin followed by no injection. Poisoning consisted of an IP injection of $25 \mathrm{mg} / \mathrm{kg}$ of cyclophosmadide. On the day following poisoning, water and saccharin were simultaneously presented to all Ss in a 20 -min preference test. The position of the tubes was switched throughout the preference test, insuring that $S$ sampled both liquids and controlling for initial position preferences.

\section{RESULTS}

Figure 1 presents the mean amount of water and saccharin consumed by each group in the 20-min preference posttest. The main result is that there was no significant difference in the amount of saccharin drunk by Groups 4 and $4 \frac{1}{2}(t=0.8)$. Also, both of these groups drank significantly more saccharin on the posttest than Group $1 / 2(t=4.3$ and 4.6$)$. Thus, among the poisoned groups, the strength of the learned aversion to saccharin was correlated with the opportunity to learn that saccharin was safe prior to being poisoned and was not correlated with the time between the last ingestion and poisoning.

There were highly significant differences in saccharin consumption between Group $S$ and all of the poisoned groups (smallest $t=5.9$ ) but no difference between the two control groups $(t=0.1)$, both of which maintained their strong initial preference for saccharin. These control groups indicate that the aversion demonstrated by the poisoned experimental groups was not a result of the trauma of injection or a change in the preference of saccharin over time.

\section{DISCUSSION}

These results replicate Kalat's earlier report, indicating that learned food aversions are reduced by the lapse of time between taste and illness, not because time weakens the trace and not because time permits interference to occur, but because the lapse of time permits $S$ to learn that the novel food is safe. We have found this interpretation to be supported even when the food in question provides no caloric benefit to the animal.

We propose that when the rat is presented with a novel food, it reacts suspiciously; it has an innate set to learn what the 
consequences are of eating the food. (Kalat's own account does not explicitly involve a concept of suspiciousness or set but some such concept would seem to be logically necessary if learned "safety" is to be taken literally.) This set is gradually dispelled in a few hours if there are no ill effects or, presumably, if ingestion leads to caloric repletion. The rat will eat as much or more of such a food on subsequent occasions. The set to learn the consequences of ingestion is also dispelled by an ensuing illness, the effectiveness of which depends upon how much safety is learned first. In short, we think that it is the set to learn about the consequences of ingestion, triggered by encountering a novel taste, that permits the rat to learn which foods are good and which foods are bad.

\section{REFERENCES}

Garcia, J., \& Koelling, R. A. Relation of cue to consequence in avoidance learning. Psychonomic Science, 1966, 4, 123-124.
Kalat, J. W. The CS-US delay gradient as a learning curve. PhD dissertation, University of Pennsylvania, 1971

Kalat, J. W., \& Rozin, P. "Salience": A factor which can override temporal contiguity in taste-aversion learning. Journal of Comparative \& Physiological Psychology, 1970, 71, 192-197.

Kalat, J. W., \& Rozin, P. "Learned safety" as a mechanism in rats' long-delay taste-aversion learning. Journal of Comparative \& Physiological Psychology, in press.

Revusky, S. H., \& Garcia, J. Learned associations over long delays. In $G, H$. Bower and J. T. Spence (Eds.), The psychology of learning and motivation: IV. New York: Academic Press, 1970.

Rozin, P., \& Kalat, J. W. Specific hungers and poison avoidance as adaptive specializations of learning. Psychological Review, $1971,78,459-486$.

Rzoska, J. Bait shyness: A study in rat behaviour. British Journal of Animal Behaviour, 1953,1, 128-135.

Wilcoxon, H. C., Dragoin, W. B., \& Kral, P. A. Illness-induced aversions in rat and quail: Relative salience of visual and gustatory cues. Science, 1971, 171, 826-828.

(Received for publication December 6, 1972.) 